\title{
A GLOBALIZAÇÃo DA POBREZA: impactos das políticas sociais do Estado Neoliberal nas democracias dos países latino-americanos
}

\author{
Maria José Galleno de Souza Oliveira \\ Professora Assistente do Departamento de Filosofia \\ e Teoria Geral do Direito da Faculdade de Direito \\ da Univursidade de São Paulo.
}

Resumo:

Mediante a vinda do novo milênio, a autora faz uma retrospectiva das nações que integram, através de seus governos. o enfrentamento da globalização imposta pela corrupção neoliberal.

Abstract:

By means of the coming of the new millenium, the author makes a retrospect in the nations that integrate, through its governments, confrontation of the globalization imposed by the neoliberal corruption.

Unitermos: Estado neoliberal; democracia nos países latino-americanos; globalização da pobreza.

Keywords: neoliberal State; democracy in the Latin America countries; globalization of the poverty.

"Por hora gostaria apenas de entender como pode ser que lantos homens, tantos burgos, tantas cidades, tantas nações suportam às vezes um tirano só, que tem apenas o poderio que eles lhe dão, que não tem o poder de prejudicá-los senão enquanto têm vontade de suportá-lo. que não poderia fazer-Ihes mal algum senão quando preferem tolerá-lo $e$ contradizê-lo. Coisa extraordinária, por cerlo; e porém lão comum que se deve mais lastimar-se do que espantar-se ao ver um milhão de homens servir miseravelmente. com o pescoço sob o jogo. não-obrigados por uma fors:a maior, mas de algum modo (ao que parece) encantados $e$ enfeitiçados, apenas pelo nome de um. de quem não devem temer o poderio pois ele é só. nem amar as qualidades pois é desumano e feroz para com eles."

(LA BOÉTIE, Etienne de. Discurso da servidão voluntiria)

1. Introdução.

Frente ao novo milênio, é oportuno revisitar conceitos e noções que ainda integram a agenda política. ideológica, social e econômica dos governos que 
atualmente regem os destinos das nações. Dentro desses conceitos, cabe refletir sobre a reestruturação dos Estados diante do finômeno da globalização imposto pela nova concepção neoliberal.

A partir dos anos 80 , com a queda do Muro de Berlim, que serviu para impulsionar o capitalismo baseado na supremacia da prosperidade econômica, da formação de mercados livres e amplos ganhos de produtividade estimulados pela competição global, foi iniciado um processo de reformas e liberação de atividades controladas pelos poderes públicos, para responder ao modelo que fundamentou o Estado de Bem-estar-social (Welfare State).

Os países latino-americanos. passam a ser laboratório de aplicação do novo modelo econômico imposto pelos países desenvolvidos, devido ao grande déficit público, os altos índices inflacionários e estagnação geral das empresas controladas pelo Estado.

Com o cenário montado, entra em ação os atores - FMI c Banco Mundial para propor soluções capazes de reduzir déficit público, combater a inflação e possibilitar a volta do crescimento econômico e social. Há necessidade de implantação de um modelo econômico global: o mito da globalização fortifica-se.

Nus Estados latino-americanos, o processo de globalização levou às privatizações e à reorganização dos serviços públicos; ampliação das empresas privadas. principalmente transnacionais: e enxugamento da estrutura administrativa estatal.

Porém, com o passar dos tempos, o modelo vitorioso do capitalismo global mostrou possuir elementos estruturais que contêm uma perversa realidade: aumento da pobreza com exclusão crescente das sociedades em paises periféricos.

Diante de tal quadro, faz-se necessário uma reflexão sobrc o redirecionamento da finalidade do Estado, que não pode deixar de visar à proteção da sociedade, em prol de uma ditadura do capitalismo global. sob pena da destruição do Estado de Direito e seus princípios fundamentais. 
2. Aspectos gerais da globalização.

A partir dos anos 80 , foi iniciado um processo de integração mundial, que para muitos não seria uma novidade, denominado globalização. 'Este processo era parte de uma idéia de reestruturação do Estado, que consistia em um processo ideológico de expansão do capitalismo, parte integrante de um projeto desenvolvido pelos teóricos do neoliberalismo.

A globalização recebeu no âmbito teórico varias denominações, tais como: aldeia global, fábrica global, terra-pátria, nave espacial, terceira onda, mundialização, desterritorialização, cidade global, etc. Enfím, uma profusão de expressões, que ao final buscam descrever e interpretar um mesmo significado: um movimento social, político, econômico, cultural, jurídico, que visa transformar e modificar todo o sistema de relações internacionais, reorientando e reformulando as decisões dos Estados-Nações, desde as mais diversas áreas da vida social até (e principalmente) os diversos sistemas produtivos e financeiros, com reflexos imediatos no sistema de emprego e nas diferenças entre países ricos e pobres.

Para Giddens, a globalização é um arranjo complexo de processos dirigido por uma mistura de influências políticas e econômicas, mudando o dia-a-dia das vidas, particulamente nos paises desenvolvidos, ao mesmo tempo em que cria novos sistemas nas sociedades atuais.

Analisando a globalização na perspectiva das relações internacionais, essa não deve ser desvinculada de outras transformações de nature za estrutural que marcaram a evolução do sistema internacional contemporâneo. Portanto, a globalização deve também ser compreendida à luz de suas relações com outros condicionamentos e processos politicos e em uma perspectiva histórica, o que permite um entendimento

I. A globalização é um processo que remota desde o século XV, com a expansão maritima-comercial européia, iniciada com a descoberta da América é a lurmação de colônias, importantes centros de atividades comerciais para fortalecimento politico dos colonizadores, pois eram fontes inesgotáveis de recursos econômicos. No século XIX, a globalização desenvolveu-se ainda mais devido à Revolução Industrial e ao surgimento de duas potências: Estados Unidos c Japão. Um outro exemplo que antecede a atual globalização, é a expansão Européia (1860) na África e na Ȧsia, que eram fontes de matéria-prima na produção de alimentos e também mercados consumidores. A expansão curopéia dos séculos XV a XIX, além de ser econômica e comercial serviu para a imposição de interesses políticos, culturais e religiosos sobre as civilizações que se encontravam nos continentes americanos, africanos e asiáticos. Nos últimos anos do século XX, a idéia de globalização ressurgiu com força total, visando ampliar o consumo, fortalecendo o capitalismo, que ingressou em uma nova etapa no processo de produção após a queda do Muro de Berlim e a derrocada dos paises que seguiam o sistema socialista implantado após a Revolução Russa, de 1917. 
mais amplo sobre a articulação do sistema de Estado-Nação que se "globalizou". passando ambos a constituirem elementos centrais do atual panorama das relações internacionais e são componentes de um mesmo espaço civilizatório em nossos dias.

É importante firmar a idéia que a expressão globalização é carregada de mitos, contradições, desigualdades e complexidades. Consegue agregar com a mesma intensidade o bem e o mal; ruptura e continuidade entre o novo e o velho capitalismo. Além disso, deve-se frisar que a globalização somente conseguiu quebrar as barreiras do sistema internacional dos Estados-Nações, devido à revolução tecnológica dos sistemas de comunicação e informação, que em segundos conecta a todos.

3. A globalização como projeto neoliberal.

Quando se fala que a globalização é parte do projeto neoliberal de ampliação do capitalismo, surge a pergunta: o que é neoliberalismo? Para respondê-la, deve-se inicialmente explicar o que significa liberalismo.

O liberalismo foi um movimento que surgiu no século XVII, com a Revolução Gloriosa (1688) da Inglaterra, tendo como seu ápice a Revolução Americana (1776) e a Revolução Francesa (1789). O liberalismo identificou-se com a luta da burguesia contra os privilégios da nobreza, limitando os poderes do rei, instituindo um conjunto de idéias defendidas pelos mais diferentes autores, tais como Locke, Montesquieu, Kant, Rousseau, Benjamin Franklin, David Ricardo, Jefferson, Bentham, Stuart Mill, Smith, Tocqueville e tantos outros que influenciaram e subverteram a História da Humanidade.

O pensamento liberal visava separar Estado e sociedade, distinguindo o público e o privado, reduzindo a intervenção estatal nas coisas privadas, surgindo então a concepção de estado mínimo. Além disso, entendia que o poder estatal deveria fundar-se no consentimento dos cidadãos, que teriam garantido direitos individuais, tais como: liberdade de pensamento, expressão e religião; prevalência do Estado de Direito; rejeição às lutas religiosas, prisões infundadas, torturas e penas cruéis. Basicamente o liberalismo fundamentou-se sob três pilares: econômico, político é ético.

Em meados do século XIX, a concepção de estado mínimo começa a ser questionada, pois apesar da implantação das principais aspirações liberais, nos grandes centros europeus, permanecem sem solução problemas de ordem econômica e social: o aumento crescente da pobreza e extremas desigualdades sociais. Contrapondo-se ao discurso liberal, surgem movimentos que defendem a intervenção do Estado (ou até a 
supressão do Estado), fortalecimento da classe operária (emergente da revolução industrial) e a garantia aos direitos coletivos.

Mas, o próprio curso da história encarrega-se de alterar o complexo caminhar da humanidade. O propalado liberalismo é obrigado a reformular o princípio diretor do estado mínimo a partir de 1929, com o crash da Bolsa de Nova York. Uma nova orientação é tomada pelo capitalismo, com a orientação de revisionar o papel do Estado na economia, considerando necessário aliar a eficiência econômica à liberdade individual, com especial atenção à justiça social. O Estado passa a intervir diretamente na economia, a fím de garantir a regulação econômica, investindo em empresas para garantir o pleno emprego.

A concepção liberal de Keynes perdura até meados dos anos 70, quando uma nova crise global questiona a Welfare State, devido às dificuldades do Estado, entre a quais responder plenamente as politicas sociais, deficit público crescente, aumento da dívida pública, inflação e crise fiscal. $\mathrm{O}$ arcabouço da Welfare State estava completamente desmistificado, quando ocorre a derrocada do Estado Socialista, com a desintegração da URSS e o esfacelamento do Leste Europeu. Tais fatos deram oportunidade para a retomada do Estado minimalista e o "nascimento" dos ideais liberais, rebatizado de Neoliberalismo.

A ideologia do neoliberalismo ${ }^{2}$ preconiza a firme convicção de combater toda e qualquer política governamental baseada na orientação keynesiana do Estado de bem-estar-social (ou Estado-providência), considerado pelos pensadores de orientação neoliberal destruidor das liberdades dos cidadãos e da competição. Alertavam que a sobrecarga do Estado levaria impreterivelmente a ingovernabilidade das democracias. Portanto, fazia-se necessidade urgente limitar a participação política, distanciar a sociedade e o sistema político e subtrair as decisões políticas administrativas ao controle político.

O Estado deveria desregulamentar, transferindo aos setores privados determinadas atividades produtivas da economia. A seguir, o Estado deveria regulamentar-se no sentido de diminuir a interferência dos poderes públicos sobre os empreendimentos privados, atuando somente como fiscalizador e regulador.

2. A obra Cuminho da servidão (1944) de Friedrich von Hayek, é considerada um dos marcos iniciais do movimento liberal. Hayek fundou a Sociedade do Mont Pèlerin (1947), organização empenhada em divulgar os princípios neoliberais. 
Os defensores das políticas neoliberais ${ }^{3}$ também pregam uma nova divisão internacional do trabalho e a globalização da produção, formando uma nova economia mundial que, por sua vez, tem como traços fundamentais: economia dominada pelo sistema financeiro e pelo investimento em escala global; processos de produção flexíveis e multilocais; baixos custos de transportes; revolução nas tecnologias de informação e de comunicação: desregulação das economias nacionais; preeminências das agências financeiras multilaterais; emergência de três grandes capitalismos transnacionais (o americano, baseado nos EUA e nas relações privilegiadas deste país com o Canadá, México e a América Latina; o japonês, baseado no Japão e nas suas relações privilegiadas com os "tigres asiáticos" e com o resto da Ásia; e o europeu, baseado na União Européia e nas relações privilegiadas desta com a Europa de Leste e com o Norte da África). ${ }^{4}$

\section{Os Estados latino-americanos e a globalização}

Nos países periféricos, principalmente os latino-americanos, a globalização tornou-se uma obrigação imposta pelas grandes potências econômicas mundiais, através de processo de estruturação desenvolvido pelo Fundo Monetário Internacional e Banco Mundial.

As razões para a imposição de políticas econômicas neoliberais nos paises periféricos ocorreram devido ao declínio do Estado da Welfare State e a necessidade de resguardar o capital privado dos grandes investidores internacionais, exigindo a reestruturação das relações, envolvendo Estado, sociedade civil e setor privado, priorizando, sobremaneira, o mercado financeiro.

Os paises latino-americanos encontravam-se em um misto de estagnação econômica e, altos índices inflacionários, além do crescente endividamento externo, com risco de não conseguirem honrar seus compromissos com os grandes bancos internacionais capitaneados pelo FMI. Diante de tal quadro, foram impostos aos Estados latino-americanos as políticas neoliberais como condição para que fossem renegociadas suas dividas. Portanto, a partir do pacto firmado, denominado de

3. Três são as cscolas através das quais o pensamento neoliberal difundiu-se: a) Escola austríaca (Iriedrich August von Hayek); b) Escola de Chicago (T. W, Schult7. Gari Becker e Milton Friedman) e; c) Escola de Virginia ou Public Choice (James M. Buchanan).

4. Conf. Boaventura de Souza Santos. A globalização e as ciências sociais, 2002, p.29. 
Consenso de Washington, ${ }^{5}$ os Estados periféricos assumiram o compromisso de implementar as seguintes orientações: abertura das economias nacionais aos mercados mundiais e adequação dos preços internos aos preços internacionais; priorização das exportações; políticas monetárias e fiscais voltadas para a redução da inflação c da dívida pública; constante vigilância sobre a balança de pagamentos; sistema normativo claro e inviolável sobre os direitos de propriedade privada; privatização do setor empresarial estatal; estabilização dos preços e política de juros altos; interferência mínima do Estado na economia; redução do peso das políticas suciais no orçamento do Estado. ${ }^{6}$

A partir de então, os governos dos paises latino-americanos, principalmente Brasil. Argentina e México, iniciaram todo um processo de convencimento nas suas sociedades locais, defendendo a globalização e disseminando os benefícios advindos dela. Entretanto, com o passar dos anos, o que se percebeu foi o crescimento econômico, financeiro e tecnológico dos países desenvolvidos e o gradual empobrecimento dos países latino-americanos, especificamente o Brasil, a Argentina e o México.

As mudanças nas economias locais dos países latino-americanos (e de modo geral às economias mundiais), beneficiou de maneira incontestável o capital financeiro, com a concentração dos grandes grupos de investidores e seu capital especulativo: e, aumento da concentração do poder econômico das empresas multinacionais.

5. Exclusão social e pobreza nos países latino-americanos.

A história dos países latino-americanos sempre foi marcada pela constatação da exclusão social e pobreza. Tal situação advém desde o colonialismo

5. O Consenso de Washington foi proposto pelo economista John Willams cm 1989, e consistiu em dez recomendações minimas de caráter geral para condução da economia latino-americana.

6. Para Boaventura de Souza Santos, a globalização econòmica encontra-se sustentada pelo consenso econômico liberal, cujas três principais inovações institucionais são: restrições drásticas à regulação estatal da cconomia, novos direitos de propriedade intermacional para investidores estrangeiros. inventoresc criadores de inovações susceptivcis de serem objeto de propriedade intelectual, subordinação dos Estados nacionais às agências multilaterais tais como o Banco Mundial, o FMI e a Organização Mundial do Comércio. Dado o caráter geral deste consenso, as receitas em que ele se traduziu foram aplicadas, ora com extremo rigor (modo da iaula de ferro), ora com alguma flexibilidade (modo dajaula de borracha). (A globalizą̧ão e as ciências sociais, 2002). 
imposto pelos países europeus, principalmente Espanha e Portugal, que a partir do final do século XV. iniciaram a expansão dos seus reinos, com a conquista da América. $\mathrm{O}$ estabelecimento dos europeus na América tinha com objetivo principal um lucrativo comércio colonial para a prosperidade da burguesia européia.

O modelo econômico imposto aos recém conquistados povos americanos foi o da exploração exaustiva de todos os recursos existentes nessas colônias. No aspecto social, os conquistadores optaram pela dizimação e submissão total dos povos nativos da América, ${ }^{7}$ destruindo quase totalmente a cultura das populações do novo mundo. Portanto, desde o início da conquista da América, as funções estavam bem definidas: seriam parceiros econômicos de um mercado desigual, com vantagens apenas para um dos lados. As nações européias obteriam na América os recursos necessários para manter o equilibrio das suas balanças comerciais sempre favorável. A exploração econômica e social latino-americana estava sedimentada, assim como loda e qualquer forma de violência poderia ser praticada para o exercício da dominação. ${ }^{8}$

Após essa pequena explicação sobre as origens do processo de exclusão e pobreza nos paises latino-americanos, discutirei sobre como a globalização e a internacionalização das economias capitalistas mundiais afıtaram o desenvolvimento social e econômico desses países, a partir dos anos 80 .

Um primeiro aspecto a ser estudado é conceituar exclusão social e pobreza no atual processo global, para então fazer um paralelo entre tais conceitos e a globalização como forma de exploração dos países latino-americanos pelo capitalismo global.

Conceituar exclusão social ${ }^{9}$ é um processo difícil. devido ao caráter subjetivo que a expressão carrega. Assim, levando em consideração os atuais patamares de desenvolvimento econômico e social da sociedade capitalista, pode-se entender a

7. Os estudiosos da história das conquistas curopéias na América estimam que havia no continente americano aproximadamente 100 milhões de indigenas, com várias civilizações das mais sofisticadas, tais como: Incas, Maias e Astecas.

8. O processo de independência da América espanhola e América portuguesa não conseguru quetrar o ciclo de exploração imposto pelos antigos conquistadores. Na rcalidade, a independência foi uma exigência do novo processo econômico: o capitalismu industrial.

9. Gerry Rogger observa que a exclusão social tem um caráter multidimensional, relacionando-se esta com as desigualdades políticas. éticas, culturais e econômicas. Portanto, é exclusão social a falta de segurança, o não-accsso à justıça e à cidadania, a falta de acesso aos bens e serviços de modo geral (público e privado). Também no mercado de trabedlho a exclusão social existe quando o individuo somente consegue uaballhar em empregos nuins e instáveis, com renda insuficiente para garantír um mínimo padrão de vida. 
exclusão social como um processo através do qual os individuos (ou grupos sociais), com ativa capacidade produtiva e de consumo, são postos de lado e para fora, afastados e marginalizado da cadeia produtiva global scm direito a ter direitos e com poucas possibilidades de reintegrar a complexa sociedade de consumo ocidental.

Quanto à pobreza, também apresenta um caráter subjetivo, variando conforme o grupo estudado. De modo geral, no estudo da pobreza é adotado o critério de medições de limites de linhas de pobreza, a partir do nível de renda e a produção de riqueza do total da população. ${ }^{10}$ Porém, compreendo que a pobreza não é somente uma questão quantitativa, mas também qualitativa, levando em consideração a diversidade humana. Portanto, a pobreza pode ser entendida como um estado de penúria, carência de oportunidade e capacidade para obter o minimo para realização de algumas necessidades elementares, tais como: nutrição, lazer, saúde, educação, vestimenta, moradia digna, familia, participação nas decisões políticas. " I

Um outro fenômeno relevante observado, que deve ser acrescentado à exclusão social e à pobreza, é o aumento das desigualdades sociais, econômicas, políticas e culturais nos países latino-americanos. Com as políticas neoliberais. as desigualdades nestes paises foram agravadas com o aumento da concentração de

10. Para a ONU e FAO, o problema da fome no Brasil agrava-se devido à concentração de renda que está acima da média dos padrões internacionais. Os níveis médios de remuneração dos $10 \%$ mais pobres da população, gira em tomo de US\$ 17. Para a FAO, deveria haver no Brasil um investimento maciço em iniciativas para a geração de emprego e renda, $\mathrm{em}$ vez de políticas compensatórias. Há divergências quanto ao número de pessoas que não têm renda suficiente para garantir alimentação adequada no Brasil. Para o Banco Mundial, há 15 milhões de miseráveis no Brasil (pessoas cuja renda não-ultrapassa o equivalente a US\$ I por dia). O IPEA (Instituto de Pesquisas Econômicas Aplicadas) identifica 22 milhỏes de indigentes (chegou a essas cifras, traçando uma linha abaixo da familia mais pobre que satisfaz seu requerimento nutricional). O Centro de Politicas Sociais da Fundação Getúlio Vargas, identifica 50 milhões de pessoas extremamente pobres. (Folha de S. Paulo, Folha Mundo, p. A23.09/jul/2002).

11. Para Dupas, "é possivel ter uma visão da pobreza como fracasso das capacidades básicas para alcançar determinados niveis minimamente aceitáveis. Isso incluiria desde as necessidades fisicamente elementares (nutrição, vestimenta, saúde) até questōes sociais mais complexas, como participar na vida comunitária desempenhando funçōes não-pagas que a sociedade tem o direito de esperar de seus membros: cuidar dos filhus, dos inválidos, participar de movimentos politicos, entre outras. Essas questões são gerais, mas sua forma concreta pode mudar de uma sociedade para outra" $O$ autor entende que "esse enfoque da pobreza baseado nas capacidade é, portanto. complementar e mais profundo do que aquele que analisa a pobreza, sendo a perspectiva da baixa renda ou da posse escassa de bens primários e recursos. Poder-sc-ia, por fim. dizer que a pobreza não é uma questão de escassez de bem-estar senão de incapacidade para conseguir bem-estar precisamente pula ausência de meios" (Economia global e exclusão social. p. 30-31). 
renda $^{12}$ pela classe mais rica. Na realidade, devido à flexibilização do trabalho, altos indices de desemprego e a incapacidade do Estado em gerir reformas concretas na estrutura política e social desses países, houve a transferência de riqueza das classes pobres para as classes ricas. Além disso, há a o aumento das desigualdades entre países latino-americanos e os países do primeiro mundo. ${ }^{13}$

Nos países latino-americanos, o aumento da exclusão social e da pobreza no final do século XX. deu-se em conseqüência da adoção das políticas neoliberais, da formação de novos paradigmas de emprego e da revolução tecnológica no setor de informação.

No âmbito individual as mudanças estruturais originaram frustrações crescentes na sociedade com piora das condições sociais. Há um sentimento de insegurança e injustiça nas massas produtivas, que se vêm desprovidas de garantias e estabilidades sociais, pelas quais tanto lutaram. Em suma, a exclusão social exprime um sentimento de ressentimento diante da impossibilidade de obter e partilhar os padrões impostos nas sociedades de consumo ${ }^{14}$ e propaladas pela globalização.

12. Os dados da exclusão social e econômica no Brasil podem ser constatados no Atlas da exclusão social - os ricos no Brasil. Neste, com dados baseados em informações dos Censos de 1980 c 2000 , constata-se que as 5 mil famílias mais ricas do pais representam $0,001 \%$ das famílias existentes e têm como patrimônio um valor que corresponde a $40 \%$ de toda a riqueza gerada por ano no país (PIB). Há uma concentração de renda de $33 \%$ nas mãos de pouco mais de $2,4 \%$, o que confirma a tesc de que o Brasil é um país onde há a maior desigualdade social e econômica do planeta.

13. Segundo relatório da ONU, realizado em parceria com a OIT. denominado A fair globalization (Uma globalização justa), a globalização aumentou as desigualdades entre países ricos e pobres. $\mathrm{O}$ relatório apesar de indicar alguns beneficios da globalização (tais como: abertura social e econômica, maior liberdade para o intercâmbio de bens, idéias e conhecimentos), aponta que houve um avanço da pobreza em praticamente todo o mundo, principalmente na América Latina, Europa Oriental e África. Significa que uma grande parte dos paises que adotaram as políticas neoliberais não conseguiram obter as vantagens da globalização. Houve um aumento significativo do desemprego, com 185 milhões de pessoas desempregadas no planeta $(6,2 \%$ da força de trabalho). O relatório também informa que um grupo minoritário de nações ( $14 \%$ da população mundial) domina metade do comércio mundial. No começo dos anos 60 , a renda per capila nas nações mais pobres era de US\$212. enquanto nos países ricos era de US\$ 11.417. Em 2002. essas cifras passaram a US\$ 267 (+26\%) e US\$ 32.339 (+ 183,3\%) respectivamente. Significa que houve transferência de renda dos paises pobres para os mais ricos. (Folhade S. Paulo, p. BI - Folha Dinheiro. 25! fevi2004).

14. Dupas compartilha com a idéia que "a sociedade contemporânea criou um sério problema ao centrar no consumo diferenciado boa parte da realização pessoal e social. Tal possibilidade de consumo transformou-se no principal sinal exterior de sucesso individual, o que faz com que o sentimento de exclusão possa ter um teor puramente relativo, ou seja, o de ıstar excluido não de necessidades consideras básicas, mas daquilo quc outras pıssoas têm. Essa sensação pode, com efeito, ocorrer em qualquer faixa de renda." (Economia glohal e exclusão social. p. 17). 
O Estado-Nação ${ }^{15}$ latino-americano faliu, tornou-se poroso, incapaz de estabelecer uma normatização comum, em garantir os processos de legitimação, assegurando limites toleráveis de desigualdades. Há perda de eficácia na capacidade de gerenciamento político, social, econômico, jurídico e cultural, em virtude do processo de globalização. ${ }^{16} \mathrm{O}$ controle político e da burocracia do Estado passam para as mãos dos grandes grupos corporativos transnacionais, bem como o controle das políticas econômicas e do espaço econômico nacional. ${ }^{17}$

As medidas impostas pelo FMI e credores, aos governos do Brasil. da Argentina e do México, exigiram reformas das constituições desses países, que levaram a cortes na educação. saúde e desenvolvimento regional; rápida privatização das empresas públicas, paraestatais e de telecomunicações; destruição de programas sociais e. gradual extinção da Previdência Social; achatamento dos salários reais (estabelecimento de um teto salarial no setor público).

Observa-se a redução dos gastos sociais em nome do combate ao déficit público e à inflação, mas ao mesmo tempo ocorre a explosão da dívida pública, relacionada em grande medida à sustentação e especulação financeira dos grandes conglomerados econômicos.

Em conseqüência, emergiu o aumento da pobreza nas áreas metropolitanas, surgindo uma nova classe de pobres: milhares de trabalhadores assalariados e funcionários burocráticos, que viviam em áreas residenciais de classe média e baixa, que foram despejados. socialmente marginalizados.

Portanto, exclusão social, pobreza e desigualdades são parte integrante dos processos de violência praticadas nos países latino-americanos, para manutenção

15. Giddens conceitua Estado-Nação como um "conjunto de formas institucionais de governo. mantendo um monopólio administrativo sobrc um território com fronteiras (limites) demarcados, seu dominio sendo sancionado por leis e por um controle direto dos meios intemos e externos de violências" (Estado-nação e a violência, p. 145).

16. Elimar Pinheiro do Nascimento entende que por trás da crise do Estado-Nação, tem-se: "de um lado. suas funçōes econômicas diminuídos, atraidas e subtraidas pelos processos e atores internacionalizados, consequiência da financeirização das riquezas e deslocamento do processo produtivo, cada vez menos nacional; e, de outro lado, suas funções sociais perdem eficiência e eficácia. Cumo a produção internacioliza-se a regulação a qual, não, pode ser mais nacional e a desigualdade aumentando. seu combate se desloca duplamente para fora (OGNs e CIA) e para baixo (entidades locais) do EstadoNação, fazendo com que abdique de sua maior função: controlar/limitar a desigualdade social. As entidades privadas, nem as públicas não-estatais. podem, por si sós, reverterem a tendência da iniqüidade social. O poder local, por sua vez, tem aqui os seus maiores limites." (Desafios da globalização, p. 84).

17. No Brasil, os últimos presidentes do Banco Central, vieram de grandes conglomerados financeiros sediados em Wall Street. 
da cadcia produtiva dos países desenvolvidos movidas pelo "inovador capitalismo global" sob o comando do FMI. Banco Mundial e empresas transnacionais.

\section{Conclusão}

Diante das reflexões expostas, resta a pergunta: Como os paises latinoamericanos poderão superar os processos de exclusão social, pobreza e desigualdade, impostos a partir da adoção de políticas neoliberais? Quais os riscos reais de uma ruptura com o projeto econômicon, social e político desenvolvido pelo FMI e Banco Mundial para os paises latino-americanos?

Para responder a tais questionamentos, faz-se necessário estudar os diferentes graus de vulnerabilidade das sociedades locais para, em seguida. fortalecêlas. Deve haver uma ampla participação política dos indivíduos que compõem o tecido social, exercendo efetivamente seus poderes, através de movimentos sociais reais, capazes de pressionar o Estado a definir políticas públicas sociais voltadas a construir uma nova dinâmica social. cultural, jurídica e econômica. As decisões e responsabilidades devem ser coletivas c compartilhadas.

A sociedade deve moldar o Estado, impondo-lhe como princípio básico: a total submissão do Estado à sociedade, pois ele existe para serví-la e não para dominá-la. A partir da adoção de tais medidas, os processos de exclusão social, pobreza e desigualdade, serão superados. $E$ os riscos advindos de uma ruptura no processo neoliberal imposto aos países latino-americanos serão minimizados.

São Paulo. setembro de 2004.

Referências Bibliográficas:

ALCÂNTARA, Lúcio. Globalização e cultura. Revista Síntese, v. 4, n. 4, p. 07-09, dez. 1999.

ARENDT, Hannah. Origens do totalitarismo. São Paulo: Companhia das Letras, 1989.

AMORIM, Ricardo Gomes: POCHMANN, Marcio. Atlas da exclusão social no Brasil. São Paulo: Cortez, 2003.

BATISTA JR., Paulo Nogueira. Mitos da "globalização" Estudos avançados, v. 32, n. 12, pp. 125-185, 1998. 
BERMAN, Marshall. Tudo que é sólido desmancha no ar: a aventura da modernidade. São Paulo: Companhia das Letras, 1986.

BOBBIO, Norberto; MATTEUCCI, Nicola; PASQUINO, Gianfranco. Dicionário de Política. 5. ed. Brasília: UnB; São Paulo: Imprensa Oficial do Estado, 2000.

BOURDIEU, Pierre (coord.). A miséria do mundo. 5. ed. Petrópolis, Rio de Janeiro: Vozes, 1997.

CASSIRER, Emest. O mito do estado. São Paulo: Códex, 2003.

CHOSSUDOVSKY, Michel. A globalização da pobreza: impactos das reformas do FMI e do Banco Mundial. São Paulo: Moderna.

CORDEN, W. Max. Economic policy, exchange rates and the international monetary system. Princeton: Princeton University Press, 1994.

DOWBOR, Landislau; IANNI, Octavio; RESENDE, Paulo-Edgar A. (Orgs.). Desafios da globalização. Petrópolis, Rio de Janeiro: Vozes, s/d.

DUPAS, Gilberto. Economia global e exclusão social: pobreza, emprego, estado e o futuro do capitalismo. 2. ed., rev. e ampl. São Paulo: Paz e Terra, 1999.

A lógica econômica global e a exclusão social. Estudos Avançados, v. 34, n. 12, p. 121-159, 1998.

A lógica econômica global e a revisão do Welfare State: a urgência de um novo pacto. Estudos Avançados, v. 33, n. 12, p. 171-183, 1998.

EICHENGREEN, Barry. Globalizing capital: a history of the international monetary system. Princeton: Princeton University Press, 1996.

FARAH, Paulo Daniel. Mundo fracassa contra a fome. Jornal Folha de S. Paulo, FolhaMundo, p. A23, domingo, 09 de junho de 2002.

FERNANDES, Fátima; ROLLI, Claudia. Ricos crescem e concentram mais renda. Jornal Folha de S. Paulo, FolhaDinheiro, p. B1, sexta-feira, 2 de abril de 2004.

FEATHERSTONE, Mike. Cultura global: nacionalismo, globalização e modernidade. Petrópolis, Rio de Janeiro: Vozes, 1994.

FURTADO, Celso. Brasil: a construção interrompida. Rio de Janeiro: Paz e Terra, 1992.

GIDDENS, Anthony. O estado-nação e a violência. São Paulo: Edusp, 2001. (Clássicos; 22) 1988.

. The third way: the renewal of social democracy. Cambridge, UK: Polity Press,

HAYEK, Friedrich A. von. O caminho da servidão. Porto Alegre: Globo, 1977. 
HOBSBAWN, Eric. A era dos extremos: o breve século XX (1914-1991). São Paulo: Companhia das Letras, 1995.

IANNI, Octavio. A sociedade global. Rio de Janeiro: ('ivilização Brasileira, 1992. Teorias da globalização. 4. ed. Rio de Janeiro: Civilização Brasileira, 1997.

INTERNATIONAL Monetary Fund. Wold economic outlook: globalization, opportunities and challenges. Washington, D.C., may 1997b.

MELO. Murilo Fiuza de. Proporção de miseráveis cresce $51 \%$ em SP. Jornal Folha de S. Paulo, FolhaRibeirão, p.C4, sexta-feira, 16 de abril de 2004.

MORAES, Reginaldo. Neoliberalismo: de onde vem, para onde vai? São Paulo: SENAC. 2001. . (Série Ponto Futuro; 6).

POCHMANN, Marcio; AMORIM, Ricardo Gomes; BARBOSA, Alexandre; SILVA, Ronnie. Atlas da exclusão social --os ricos no Brasil. São Paulo: Cortez, 2004. v. 3.

REDAÇÃO, da. Globalização aumenta desigualdade, diz ONU. Folha de S. Paulo, FolhaDinheiro, p. B1, quarta-feira, 25 de fevereiro de 2004.

SANTOS, Boaventura de Sousa (Org.). A globalização e as ciências sociais. São Paulo: Cortez. 2002.

Cortez, 1999.

Pela mão de Alice: o social e o político na pós-modernidade. 6. ed. São Paulo:

SOROS, George. A crise do capitalismo: as ameaças aos valores democráticos; as soluções para o capitalismo global. 3. ed. Rio de Janeiro: Campus. 1998.

VIEIRA, Liszt. Cidadania global e estado nacional. DADOS: Revista de Ciêncius Sociais, v. 42, n. 3, p. 395-419, 1999.

VILLA, Marco Antônio. As matrices históricas da globalização. Revista Síntese, a. 4. n. 4, p. 11-15, dez. 1999. 